\section{Modified Treatment for Epidemic Keratoconjunctivitis}

\author{
Shaaban Abd-Elhamid Mehany Elwan ${ }^{1,2 *}$ \\ ${ }^{1}$ Department of Ophthalmology, Faculty of Medicine, Minia University, \\ El-Minia, Egypt
}

${ }^{2}$ Department of Ophthalmology, Security Forces Hospital, Riyadh, Kingdom of Saudi Arabia

\begin{abstract}
Purpose: The purpose of this study to compare between the modified and the ordinary method of treatment for EKC.

Study Design: Prospective randomized clinical study.

Methods: Three hundred fifty patients of EKC were enrolled in a prospective interventional study. The diagnosis was made by clinical picture and laboratory investigations. Group 1 had two hundred patients 120 males, 80 females (age from 18 to 60 years old) were treated by the modified method (Povidone lodine $5 \%$ eye irrigation) and group 2 had one hundred fifty patients 100 males, 50 females (age from 18 to 58 years old) were treated with the ordinary method (normal saline eye wash). Patients were followed for 3 months up to 2 years. The main outcomes were improvement in clinical picture and recovery.
\end{abstract}

Results: Ocular symptoms and signs were improved with clinical significant better results for group 1 than group 2. One hundred eighty patients $(90 \%)$ of group 1 had spontaneous recovery, 14 patients $(7 \%)$ had recovery after use of topical steroids, and 6 patients $(3 \%)$ had recovery with subepithelial corneal infiltrates. Ninety patients $(60 \%)$ of group 2 had spontaneous recovery, 15 patients $(10 \%)$ had recovery after use of topical steroids, and 45 patients ( $30 \%)$ had recovery with subepithelial corneal infiltrates.

Conclusion: The modified method of treatment had significantly better results than the ordinary one regarding to ocular symptoms and signs improvement as well as patients recovery $(P<0.001)$.

Keywords: Adenovirus; Epidemic Keratoconjunctivitis; lodine; Povidone; Spontaneous recovery; Subepithelial corneal infiltrates

*Corresponding author: Shaaban Abd-Elhamid Mehany Elwan, Department of Ophthalmology, Faculty of Medicine, Minia University, 61519, El-Minia, Egypt, Tel: 00966509507738; Fax: 00966114764757; E-mail: shaabanhamid29@gmail. com / shaabanhamid29@mu.edu.eg

Citation: Elwan Shaaban (2020) Modified Treatment for Epidemic Keratoconjunctivitis. J Ophthalmic Clin Res 7: 070.

Received: June 03, 2020; Accepted: June 12, 2020; Published: June 19, 2020

Copyright: (c) 2020 Elwan Shaaban. This is an open-access article distributed under the terms of the Creative Commons Attribution License, which permits unrestricted use, distribution, and reproduction in any medium, provided the original author and source are credited.

\section{Introduction}

Epidemic Keratoconjunctivitis (EKC) is a form of adenovirus ophthalmic infection. EKC is highly infectious and has a frequency to happen in epidemics. Higher than 54 human serotypes of adenovirus have been separated, and sorted into six species based on biological and genetic properties from (A-F). Not less than 19 adenovirus serotypes can cause EKC, the most common known serotypes includes 8,19 , and 37 and less frequently serotypes $9,10,13,15,17,20,22$ $30,32,33$ and 39 from species D, serotypes 2-5 from species $C$ and serotypes 7, 16 and 21 from species B1 [1].

Adenovirus serotypes 8 and 19 are accountable for EKC and they are extremely infectious for about two weeks [2]. As well as serotype type 37 is a major agent of EKC and was known to be the main cause of the disease in Japan [3]. The incubation period is ranged from 2 days and up to two weeks, the patient may remain infectious for two weeks after symptoms emerged. It is identified by conjunctivitis and keratitis. Conjunctivitis has acute onset of the following symptoms; watering discharge, redness, foreign body sensation and discomfort. The signs consist of lid edema, follicular conjunctivitis, and subconjunctival hemorrhage and pseudo membrane formation with a preauricular lymphadenopathy in the majority of patients [4]. EKC may be presented in both of eyes in about $60 \%$ of cases [5]. Keratitisoccurs in around $80 \%$ of cases and divided into three stages: - Stage one, which appears in the second week or within 7-10 days of symptoms onset and in the form of diffuse punctate epithelial Keratitis. Stage two, which evolve under the epithelial lesions in the form of focal white subepithelial infiltrates. They are assumed to be immune response to the virus and might be associated with mild anterior uveitis [6]. Stage three, in the form of anterior stromal infiltrates which may persist for months and even years [7].

EKC is not only presented in adults, but it is also presented in all age groups with no gender predilection [4]. EKC outbreaks tend to appear in closed places (e.g., hospitals, schools, camps, factories, nursing homes, work places) [8]. EKC transmission is due to direct contact with eye secretions but air droplets and swimming pools play a role in disease transmission $[3,9]$. Epidemics can be started in outpatient eye clinics by direct contact with contaminated diagnostic tools such as applanation tonometer to the client eyes during ophthalmological examination. The diagnosis of EKC is based mainly on history and clinical picture but cell culture in combination with immunofluorescence staining (CC-IFA) is a good tool for diagnosis [10]. As well as Polymerase Chain Reaction (PCR) is very specific in detection of adenovirus antigen $[11,12]$. These methods are the most accurate way to confirm diagnosis however, many physicians lack diagnostic lab orders due to the cost and time delay. Rapid diagnosis of EKC has evolved with Rapid Pathogen Screening (RPS) Adeno Detector with instant results and it is useful in exact diagnosis of EKC patients in office [10]. EKC is a self-limiting disease spontaneously resolve within 1-3 weeks without significant complications, but in 20$50 \%$ of cases corneal infiltrates can persist for some weeks or even 
months and sometimes up to two years that lead to drop of visual acuity and significant glare as well as conjunctival scarring and symblepharon may happen in case of membranous conjunctivitis $[13,14]$.

It is significant to put in consideration people health education as adenovirus serotype 19 may remain viable for 5 weeks and resist against standard disinfectants such as isopropyl alcohol (70\%) [15]. The best way for prevention of EKC spread is protection as well as improvement of hygienic habits including repeated hand washing and infected patients should not share personal belongings such as towels and cosmetics $[16,17]$.

\section{Aim of the Work}

Because EKC is much common in the Middle East and in Saudi Arabia and by reviewing the literature to the best of our knowledge, there is no currently approved antiviral treatment for EKC. We conducted this study to compare the results between the modified and the ordinary method for treatment for EKC.

\section{Patients and Methods}

Three hundred fifty patients suffering from EKC were enrolled in the study. Their diagnosis was made by clinical picture and laboratory investigations including Rapid Pathogen Screening (RPS) Adeno detector for confirmation. Group 1 had two hundred patients 120 males, 80 females (age from 18to 60 year olds) were treated by the modified method and group 2 had one hundred fifty patients 100 males, 50 females (age from 18 to 58 years) were treated with the ordinary method. The study was done at a period from November 2014 to April 2020 in Security Forces Hospitals Program (SFHP), Riyadh, Saudi Arabia. Patients were followed up for 3 months up to 2 years. The main outcomes were improvement in patient's clinical picture and recovery. All patients signed consent for inclusion in the study and the study was approved by the Institutional Review Board of SFHP (IRB-SFHP-RIYADH) with accreditation number (H-01-R-096) and it was in agreement with Declaration of Helsinki Tents.

\section{Inclusion criteria}

Including adult patients with 18 to 60 years old, patients with BCDVA of $\geq 20 / 80$ in the study eye, if the patient has bilateral EKC only one eye (the more symptomatized eye) included in the study and the other eye underwent the same treatment but not included and patients attending all the required follow up visits were included in the study.

\section{Exclusion criteria}

Children and patients $<18$ years old, patients with ocular infection rather than $\mathrm{EKC}$, patients with corneal ulceration or bacterial keratitis, immunocompromised patients, glaucoma and patients not attending the required follow up visits.

All cases were diagnosed by clinical symptoms and signs as shown in tables $1 \& 2$ conjunctival smear for some suspected patients who revealed lymphocytes predominance. Slit lamp examination and visual acuity measurement were done and grading of ocular symptoms and signs were estimated according to severity into normal, mild, moderate or severe as normal= no abnormality, mild $=$ subtle abnormality, moderate $=$ obvious abnormality and severe $=$ marked abnormality according to clinical examinations and patients questionnaire as well as documented by photography. The patients were randomly divided by coin toss in a ratio of $4: 3$ randomization patterns into 2 groups and the clinician was masked to the treatment group. Group 1 in which patients were treated by the modified method (Povidone Iodine $5 \%$ eye wash) and group 2 in which patients were treated by the ordinary method (normal saline eye wash).

\begin{tabular}{|c|c|c|c|c|c|c|c|c|}
\hline \multirow[b]{2}{*}{ Severity grading } & \multicolumn{4}{|c|}{ Group I (N=200) } & \multicolumn{4}{|c|}{ Group II } \\
\hline & Normal & mild & moderate & severe & Normal & mild & moderate & severe \\
\hline Lid swelling & $80(40 \%)$ & $70(35 \%)$ & $40(20 \%)$ & $10(5 \%)$ & $65(43.3 \%)$ & $55(36.67 \%)$ & $24(16 \%)$ & $6(4 \%)$ \\
\hline Red eyes & $0(0.0 \%)$ & $60(30 \%)$ & $110(55 \%)$ & $30(15 \%)$ & $0(0.0 \%)$ & $45(30 \%)$ & $85(56.67 \%)$ & $20(13.3 \%)$ \\
\hline Watery discharge & $0(0.0 \%)$ & $70(35 \%)$ & $120(60 \%)$ & $10(5 \%)$ & $0(0.0 \%)$ & $50(33.3 \%)$ & $93(62 \%)$ & $7(4.7 \%)$ \\
\hline Photophobia & $40(20 \%)$ & $60(30 \%)$ & $80(40 \%)$ & $20(10 \%)$ & $30(20 \%)$ & $45(30 \%)$ & $65(43.3 \%)$ & $10(6.7 \%)$ \\
\hline Foreign body sensation & $0(0.0 \%)$ & $140(70 \%)$ & $50(25 \%)$ & $10(5 \%)$ & $0(0.0 \%)$ & $106(70.7 \%)$ & $36(24 \%)$ & $8(5.3 \%)$ \\
\hline Eye discomfort & $0(0.0 \%)$ & $120(60 \%)$ & $50(25 \%)$ & $30(15 \%)$ & $0(0.0 \%)$ & $90(60 \%)$ & $35(23.3 \%)$ & $25(16.7 \%)$ \\
\hline
\end{tabular}

Table 1: Baseline ocular symptoms.

Normal $=$ no abnormality, mild $=$ subtle abnormality, moderate $=$ obvious abnormality and severe $=$ marked abnormality

\begin{tabular}{|c|c|c|c|c|c|c|c|c|}
\hline & \multicolumn{4}{|c|}{ Group I } & \multicolumn{4}{|c|}{ Group II } \\
\hline Severity grading & Normal & mild & moderate & severe & Normal & mild & moderate & severe \\
\hline Lid edema & $90(45 \%)$ & $50(25 \%)$ & $52(26 \%)$ & $8(4 \%)$ & $70(46.7 \%)$ & $35(23.3 \%)$ & $40(26.7 \%)$ & $5(3.3 \%)$ \\
\hline Follicular conjunctivitis & $0(0.0 \%)$ & $55(27.5 \%)$ & $125(62.5 \%)$ & $20(10 \%)$ & $0(0.0 \%)$ & $30(20 \%)$ & $100(66.7 \%)$ & $20(13.3 \%)$ \\
\hline Sub-Conjunctival hemorrhage & $0(0.0 \%)$ & $55(27.5 \%)$ & $120(60 \%)$ & $25(12.5 \%)$ & $0(0.0 \%)$ & $55(36.7 \%)$ & $75(50 \%)$ & $20(13.3 \%)$ \\
\hline Pseudo membrane formation & $50(25 \%)$ & $120(60 \%)$ & $22(11 \%)$ & $8(4 \%)$ & $40(26.7 \%)$ & $90(60 \%)$ & $16(10.7 \%)$ & $4(2.6 \%)$ \\
\hline Preauricular lymphadenopathy & $15(7.5 \%)$ & $130(65 \%)$ & $55(27.5 \%)$ & $0(0.0 \%)$ & $10(6.7 \%)$ & $100(66.7 \%)$ & $40(26.6 \%)$ & $0(0.0 \%)$ \\
\hline Punctate epithelial keratitis & $0(0.0 \%)$ & $20(10 \%)$ & $150(75 \%)$ & $30(15 \%)$ & $0(0.0 \%)$ & $5(3.3 \%)$ & $120(80 \%)$ & $25(16.7 \%)$ \\
\hline
\end{tabular}

Table 2: Base line Ocular sings. 


\section{The modified method}

The eye was topically anesthetized, then eye wash with Povidone Iodine $5 \%$ (Povidone-iodine, Alcon) eye irrigation every day until the patients recovered. Manual removal of pseudo membranes with nontoothed forceps and cotton tipped applicator on slit lamp. Antibiotic eye drops (moxifloxacin 0.5\%) QID. Lubricant eye drops (tears natural free minims eye drops) QID. Cold compresses. Topical corticosteroid eye drops (fluorometholone $0.1 \%$ ) QID in cases of subepithelial infiltrates or pseudomemrane formation.

\section{The ordinary method}

The same way of management except the eye wash was with normal saline only and not using Povidone Iodine 5\%. Steroids were used for symptomatic relief but it does not lower the disease pathway. It suppress the corneal inflammation, improve overall comfort but they also prolong clearance of the virus and the lesions may reoccur if steroid is prematurely discontinued [18].

\section{Statistical analysis}

Statistical analysis was performed with Microsoft office excels. Data were expressed as mean \pm Standard Deviation (SD). Unpaired $t$ test was used for comparison between symptoms and signs parameters. Graph Pad Prism 5 program was used for figure construction. $P$ value $<0.05$ was considered statistically significant.

\section{Results}

Table 3 shows the patient's demographic data in which group 1 included 200 patients 120 males and 80 females with mean age of $50 \pm 9.2$, range (18-60 years old) and 110 patients right eyes and 90 left eyes while group 2 included 150 patients 100 males and 50 females with mean age of $49 \pm 10.2$, range (18-58 years old) and 80 patients right eyes and 70 left eyes.

\begin{tabular}{|l|c|c|c|}
\hline \multicolumn{1}{|c|}{ Items } & Group I & Group II & Total \\
\hline Number of patients & 200 & 150 & 350 \\
\hline Sex (M/F) & $120 / 80$ & $100 / 50$ & $220 / 130$ \\
\hline Age (years ) mean \pm SD range & $50 \pm 9.2$ & $49 \pm 10.2$ & $49.5 \pm 8.5$ \\
& $(18-60)$ & $(18-58)$ & $(18-60)$ \\
\hline Laterality (R/L) & $110 / 90$ & $80 / 70$ & $190 / 160$ \\
\hline
\end{tabular}

Table 3: Patients demographic data.

The mean duration of illness before patients enrollment in the study was $3.2 \pm 1.8$ days with range (2-7) days. As shown in table 1, the baseline ocular symptoms in both of groups with no clinically significant differences all over the checked parameters where, lid swelling was present in $60 \%$ of patients in group 1 and in $56.7 \%$ of patients in group 2 . Red eyes were present in $100 \%$ of patients for both groups as well as watery discharge. Photophobia was present in $80 \%$ of patients for both of groups. Foreign body sensation as well as eye discomfort was present in $100 \%$ of patients in both groups. Table 2 shows the base line ocular signs with also no clinically significant differences for all of the checked parameters in both groups where lid edema was present in 55\% of patients in group 1 and in 53.3\% of patients in group 2. Follicular conjunctivitis as well as subconjunctival hemorrhage was present in $100 \%$ of eyes in both groups.
Pseudo membranes were found in $75 \%$ of eyes in group 1 and in $73.3 \%$ in group 2. Preauricular lymphadenopathy was found in $92.5 \%$ in group 1 and in $93.3 \%$ in group 2 while punctate epithelial Keratitis was present in $100 \%$ of eyes in both groups.

In comparing ocular symptoms one week to 10 days after treatment as shown in table 4 , there was clinically significant differences between both groups in which all checked parameters were improved, with better results in group 1. Lid swelling was present in $20 \%$ of patients and $80 \%$ was normal in group 1, while it was present in $50 \%$ of patients and $50 \%$ was normal in group 2 . Red eyes was present in $35 \%$ of patients and $65 \%$ was normal in group 1 . While, it was present in $80 \%$ of patients and $20 \%$ was normal in group 2 . Watery discharge was present in $15 \%$ of patients, and $85 \%$ was normal in group 1 . While it was present in $40 \%$ of patients and $60 \%$ was normal in group 2. Photophobia was present in $30 \%$ of patients and $70 \%$ was normal in group 1 . While it was present in $50 \%$ of patients and $50 \%$ was normal in group 2. Foreign body sensation was present in $25 \%$ of patients and $75 \%$ was normal in group 1 . While it was present in $40 \%$ of patients and $60 \%$ was normal in group 2 . Eye discomfort was present in $5 \%$ of patients and $95 \%$ was normal in group 1 . While it was present in $20 \%$ of patients and $80 \%$ was normal in group 2 . Table 5 shows ocular signs one week to 10 days after treatment with also, clinically significant difference between the groups with better results in group 1. Lid edema was present in $25 \%$ of patients and $75 \%$ was normal in group 1, while it was present in $40 \%$ of patients and $60 \%$ was normal in group 2. Follicular conjunctivitis was present in $30 \%$ of patients and $70 \%$ was normal, while it was present in $36.6 \%$ and $63.4 \%$ was normal in group 2. Sub-Conjunctival hemorrhage was present in $75 \%$ of patients and $25 \%$ was normal in group 1 , while it was present in $76.7 \%$ and $23.3 \%$ was normal in group 2. Pseudo membrane was present in $40 \%$ of patients and $60 \%$ was normal in group 1, while it was present in $60 \%$ of patients and $40 \%$ was normal in group 2. Preauricular lymphadenopathy was present in $90 \%$ of patients and $10 \%$ was normal in group 1 and 2 respectively. Punctate epithelial keratitis was present with moderate degree in $60 \%$, mild degree in $35 \%$ and with severe degree in $5 \%$ of patients in group 1 , while it was present with moderate degree in $73.3 \%$, mild degree in $14.7 \%$ degree and with severe degree in $12 \%$ of patients in group 2 . Table 6 shows ocular signs 3 months after treatment, in which White subepithelial infiltrates was present in 3\% of patients and $97 \%$ was normal in group 1, while it was present in $30 \%$ of patients and $70 \%$ was normal in group 2 with clinically significant difference. Anterior stromal infiltrate was present in $3.3 \%$ of patients and $96.7 \%$ was normal in group 2, while it was not present in group 1. Table 7 and figure 1 shows the final recovery outcomes in which spontaneous recovery without corneal opacities was achieved in $90 \%$ of patients in group 1 , while it was achieved in $60 \%$ of patients in group 2 with clinically significant difference $(\mathrm{p} \leq 0.001)$. Recovery with corticosteroid was achieved in $7 \%$ of patients in group 1, while it was achieved in $10 \%$ of patients in group 2 with no clinical significant difference $(\mathrm{p}=0.9)$. Recovery with subepithelial corneal infiltrates was achieved in $3 \%$ of patients in group 1, while it was achieved in $30 \%$ of patients in group 2 with high clinical significant difference $(\mathrm{p} \leq 0.0001)$. 


\begin{tabular}{|l|c|c|c|c|c|c|c|c|}
\hline & \multicolumn{4}{|c|}{ Group I (N=200) } & \multicolumn{4}{c|}{ Group II (N=150) } \\
\hline Severity grading & Normal & mild & moderate & severe & Normal & mild & moderate & severe \\
\hline Lid swelling & $160 * *(80 \%)$ & $36 *(18 \%)$ & $4 * *(2 \%)$ & $0 *(0.0 \%)$ & $75(50 \%)$ & $50(33.4 \%)$ & $20(13.3 \%)$ & $5(3.3 \%)$ \\
\hline Red eyes & $130 * *(65 \%)$ & $60(30 \%)$ & $6 * *(3 \%)$ & $4 * * *(2 \%)$ & $30(20 \%)$ & $45(30 \%)$ & $60(40 \%)$ & $15(10 \%)$ \\
\hline Watery discharge & $170 * *(85 \%)$ & $25 *(12.5 \%)$ & $5 * *(2.5 \%)$ & $0 *(0.0 \%)$ & $90(60 \%)$ & $30(20 \%)$ & $25(16.7 \%)$ & $5(3.3 \%)$ \\
\hline Photophobia & $140 * *(70 \%)$ & $40 *(20 \%)$ & $18 * *(9 \%)$ & $2 *(1 \%)$ & $75(50 \%)$ & $20(13.3 \%)$ & $45(30 \%)$ & $10(6.7 \%)$ \\
\hline Foreign body sensation & $150 *(75 \%)$ & $40(20 \%)$ & $10 *(5 \%)$ & $0(0.0 \%)$ & $90(60 \%)$ & $30(20 \%)$ & $30 *(20 \%)$ & $0(0.0 \%)$ \\
\hline Eye discomfort & $190 *(95 \%)$ & $10 *(5 \%)$ & $0 *(0.0 \%)$ & $0(0.0 \%)$ & $120(80 \%)$ & $20(13.3 \%)$ & $10(6.7 \%)$ & $0(0.0 \%)$ \\
\hline
\end{tabular}

Table 4: Ocular symptoms one week to 10 days after treatment.

* $\mathrm{P}=<0.05, * * \mathrm{P}=<0.01$ and $* * * \mathrm{P}=<0.001$

\begin{tabular}{|c|c|c|c|c|c|c|c|c|}
\hline \multirow[b]{2}{*}{ Severity grading } & \multicolumn{4}{|c|}{ Group I } & \multicolumn{4}{|c|}{ Group II } \\
\hline & Normal & mild & moderate & severe & Normal & mild & moderate & severe \\
\hline Lid edema & $150 *(75 \%)$ & $40(20 \%)$ & $10 * *(5 \%)$ & $0 *(0.0 \%)$ & $90(60 \%)$ & $27(18 \%)$ & $30(20 \%)$ & $3(2 \%)$ \\
\hline Follicular conjunctivitis & $140 *(70 \%)$ & $30(15 \%)$ & $20(10 \%)$ & $10 *(5 \%)$ & $95(63.4 \%)$ & $20(13.3 \%)$ & $20(13.3 \%)$ & $15(10 \%)$ \\
\hline Sub-Conjunctival hemorrhage & $50(25 \%)$ & $45(22.5 \%)$ & $90(45 \%)$ & $15(7.5 \%)$ & $35(23.3 \%)$ & $30(20 \%)$ & $70(46.7 \%)$ & $15(10 \%)$ \\
\hline Pseudo membrane formation & $120 * *(60 \%)$ & $60 * *(30 \%)$ & $15 *(7.5 \%)$ & $5 *(2.5 \%)$ & $60(40 \%)$ & $80(53.4 \%)$ & $8(5.3 \%)$ & $2(1.3 \%)$ \\
\hline Preauricular lymphadenopathy & $20(10 \%)$ & $140(70 \%)$ & $40(20 \%)$ & $0(0.0 \%)$ & $15(10 \%)$ & $110(73.3 \%)$ & $25(16.7 \%)$ & $0(0.0 \%)$ \\
\hline Punctate epithelial keratitis & $0(0.0 \%)$ & $70 * *(35 \%)$ & $120 *(60 \%)$ & $10 * *(5 \%)$ & $0(0.0 \%)$ & $22(14.7 \%)$ & $110(73.3 \%)$ & $18(12 \%)$ \\
\hline
\end{tabular}

Table 5: Ocular sings one week to 10 days after treatment.

$* \mathrm{P}=<0.05, * * \mathrm{P}=<0.01$ and $* * * \mathrm{P}=<0.001$

\begin{tabular}{|c|c|c|c|c|c|c|c|c|}
\hline & \multicolumn{4}{|c|}{ Group I } & \multicolumn{4}{|c|}{ Group II } \\
\hline Severity grading & Normal & mild & moderate & severe & Normal & mild & moderate & severe \\
\hline White subepithelial infiltrates & $194 * * *(97 \%)$ & $4 * * *(2 \%)$ & $2 * * *(1 \%)$ & $0(0.0 \%)$ & $45(30 \%)$ & $90(60 \%)$ & $15(10 \%)$ & $0(0.0 \%)$ \\
\hline Anterior stromal Infiltrates & $200(100 \%)$ & $0(0.0 \%)$ & $0(0.0 \%)$ & $0(0.0 \%)$ & $145(96.7 \%)$ & $3(2 \%)$ & $2(1.3 \%)$ & $0(0.0 \%)$ \\
\hline
\end{tabular}

Table 6: Ocular signs three months after treatment.

$* * * \mathrm{P}=<0.001$

\begin{tabular}{|l|c|c|c|}
\hline \multicolumn{1}{|c|}{ Findings } & Group I & Group II & P value \\
\hline Spontaneous recovery & $180(90 \%)$ & $30(20 \%)$ & $\leq 0.0001$ \\
\hline Recovery with corticosteroid & $14(7 \%)$ & $15(10 \%)$ & 0.9 \\
\hline $\begin{array}{l}\text { Recovery with sub-epithelial } \\
\text { corneal infiltrates }\end{array}$ & $6(3 \%)$ & $105(70 \%)$ & $\leq 0.0001$ \\
\hline
\end{tabular}

Table 7: Final recovery outcomes.

\section{Discussion}

EKC is highly infectious adenoviral disease producing ocular discomfort and its ordinary treatment didn't affect the disease pathway and its sequally with subepithelial opacities may persist for months or even years leading to blurring of vision [7]. EKC happens sporadically in families, schools, health units and in outbreaks. There isn't proved treatment for EKC [19]. Papetropoulou et al., postulated that, it is necessary to detect the disease on time, treat it adequately and carry out the antiepidemic measures to cut the ways for disease spread [9]. EKC acquired and shared by patients and health care staff provider during disease outbreaks [20]. The management of EKC is only supportive and unsatisfactory and there is no evidence that proves effectiveness of antiviral agents [21]. The incubation period ranges from 2 to 14 days, and shedding of virus occurs from last days of incubation period to 2 weeks after disease onset. Hand washing, use of gloves, and instruments disinfection can decrease adenovirus spread [4].

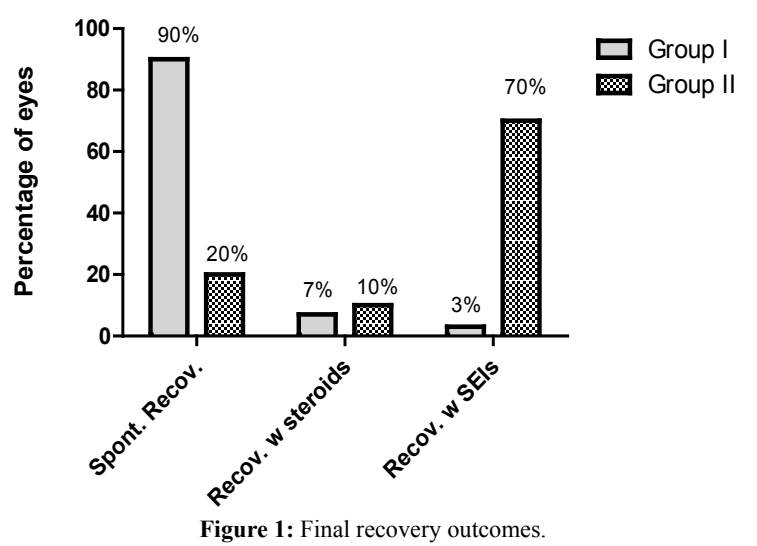


The management of EKC includes palliative treatment, in the form cool compresses, artificial tears, topical antibiotics, topical non-steroidal anti-inflammatory drugs (NSAIDS) and topical corticosteroids if EKC presented with corneal subepithelial infiltrates, pseudomemrane or iridocyclitis. Steroids suppress the inflammation of the conjunctiva and cornea and hence produce symptomatic relief, but they don't reduce the disease pathway. However, it enhances the viral replication and prolongs its shedding [18,22]. NSAIDS do not affect adenovirus clearance but have not demonstrated better results than artificial tears[23, 24]. Romanowski et al., [25] found that cyclosporine A $0.5 \%$ or $2.0 \%$ significantly reduce subepithelial corneal infiltrates in a rabbit model. However, topical cyclosporine A increased adenoviral replication, similar to the results reported with corticosteroid use. Antiviral compounds such as Ribavirin was found to have low efficacy against the three predominant adenovirus serotypes $(8$, 19 and 37) [26]. Hillenkamp et al., [27] studied the effectiveness of cidofovir $1 \%$ eye drops either with or without cyclosporine A $1 \%$ and proved that cidofovir lowers the incidence of corneal opacities severity. However, its clinical use was limited because of its local toxicity. Tabbara et al., [28] concluded that local ganciclovir $0.15 \%$ eye ointment is effective and safe for management of adenoviral conjunctivitis. N-chlorotaurine had shown proof of antimicrobial activity against EKC as well as tolerated well with minimum side effects [29].

Povidone-iodine (PVP-I) had concluded promising results in treatment of EKC. It was proved that Povidone-iodine has a broad spectrum antimicrobial efficacy against bacteria, fungi, viruses and protozoa [30,31]. Pelletier et al., [32] studied a local combination of $0.4 \%$ Povidone-iodine and $0.1 \%$ Dexamethasone and concluded that all patients had fast relive of symptoms with lowering of the viral titers. Melton et al., [33] reported the treatment of EKC with Povidone-iodine $5 \%$ few drops followed by saline eye irrigation can preserve visual function and reduce viral spread. Povidone-iodine is potentially useful, but large-scale trials are lacking that encourage us to use this inexpensive agent (Povidone-iodine 5\%) for eye irrigation after topical anesthetic eye drops to overcome its local stinging effect with satisfactory results as patients symptoms and signs significantly improved in group 1 (Povidone-iodine 5\%) than in group 2 (ordinary method) as well as the final recovery outcome results were superior in group 1 than group 2. Our results were in agreement with Kovalyuk et al., [34] in which they reported reduction in patient's symptoms and signs as well as reduction in recovery time and viral titer in their study group managed by a combination of Povidone-iodine $1 \%$ and dexamethasone $0.1 \%$ drops QID. Our results also were in accordance with results of Trinavarat et al., [35] in which they reported recovery of ocular symptoms and discomfort in $77 \%$ of their patients within a week of treatment using Povidone-iodine 2\% eye drops QID for a week; however we used Povidone-iodine $5 \%$ daily eye wash with promising results and minimal side effects.

\section{Conclusion}

We concluded that the modified method of treatment we used was a trial to alleviate the patient discomfort and facilitate recovery. It had significantly better results than the ordinary one in improving patients' symptoms and signs as well as decreasing the subepithelial corneal infiltrates that can burden vision $(P<0.001)$.

\section{Acknowledgments}

Author would like to acknowledge the overwhelming support from all of my colleges in Ophthalmology department, Faculty of Medicine, Minia University, El-Minia, Egypt and Ophthalmology Department, Security Forces Hospital, Riyadh, SA.

\section{Conflicts of Interests}

The author declares that he did not have either conflict of interests or financial interests, as well as this data, have not been published before.

\section{References}

1. Lenaerts L, Clercq ED, Naesens L (2008) Clinical features and treatment of adenovirus infections. Rev Med Virol 18: 357-374.

2. Barnard DL, Hart JC, Clarke SK (1973) Outbreak in Bristol of conjunctivitis caused by adenovirus type 8 , and its epidemiology and control. $\mathrm{Br}$ Med J 2: 165-169.

3. Takeuchi S, Itoh N, Uchio E, Tanaka K, Kitamura N, et al. (19990 Adenovirus strains of subgenus D associated with nosocomial infection as new etiological agents of epidemic keratoconjunctivitis in Japan. J Clin Microbiol 37: 3392-3394.

4. Rubenstein JB, Tannan A (2013) Conjunctivitis: Infectious and Noninfectious. Ophthalmology: Expert Consult: Online and Print, pg no. 180.

5. Weiss A, Brinser JH, Nazar-Stewart V (1993) Acute conjunctivitis in childhood. J Pediatr 122: 10-14.

6. Rajaiya J, Chodosh J (2006) New paradigms in infectious eye disease: adenoviral keratoconjunctivitis. Arch Soc Esp Oftalmol 81: 493-498.

7. Kanski JJ, Bowling B (2012) Synopsis of Clinical Ophthalmology. Expert Consult-Online and Print, Elsevier health sciences.

8. D'Angelo LJ, Hierholzer JC, Holman RC, Smith JD (1981) Epidemic keratoconjunctivitis caused by adenovirus type 8 : epidemiologic and laboratory aspects of a large outbreak. Am J Epidemiol 113: 44-49.

9. Papapetropoulou M, Vantarakis A (1998) Detection of adenovirus outbreak at a municipal swimming pool by nested PCR amplification. J Infect 36: 101-103.

10. Sambursky R, Tauber S, Schirra F, Kozich K, Davidson R, et al. (2006) The RPS adeno detector for diagnosing adenoviral conjunctivitis. Ophthalmology 113: 1758-1764.

11. Cheung D, Bremner J, Chan J, (2003) Epidemic kerato-conjunctivitis--do outbreaks have to be epidemic? Eye (Lon) 17: 356-363.

12. Lee CS, Lee AY, Akileswaran L, Stroman D, Najafi-Tagol K, et al. (2018) Determinants of outcomes of adenoviral keratoconjunctivitis. Ophthalmology125: 1344-1353.

13. Ariga T, Shimada Y, Shiratori K, Ohgami K, Yamazaki S, et al. (2005) Five new genome types of adenovirus type 37 caused epidemic keratoconjunctivitis in Sapporo, Japan, for more than 10 years. J Clin Microbiol 43: 726-732.

14. Kaufman HE (2011) Adenovirus advances: new diagnostic and therapeutic options. Curr Opin Ophthalmol 22: 290-293.

15. Rutala WA, Weber DJ (2008) Guideline for disinfection and sterilization in healthcare facilities, 2008, Department of Health and Human Services, USA.

16. Gordon YJ, Gordon RY, Romanowski E, Araullo-Cruz TP (1993) Prolonged recovery of desiccated adenoviral serotypes 5, 8, and 19 from plastic and metal surfaces in vitro. Ophthalmology 100: 1835-1840. 
17. Lakkis C, Lian KY, Napper G, Kiely PM (2007) Infection control guidelines for optometrists 2007. Clin Exp Optom 90: 434-444.

18. Romanowski EG, Yates KA, Gordon YJ (2001) Short-term treatment with a potent topical corticosteroid of an acute ocular adenoviral infection in the New Zealand white rabbit. Cornea 20: 657-660.

19. Nagington J, Sutehall GM, Whipp P (1983) Tonometer disinfection and viruses. Br J Ophthalmol 67: 674-676.

20. Boerner CF, Lee FK, Wickliffe CL, Nahmias AJ, Cavanagh HD, et al. (1981) Electron microscopy for the diagnosis of ocular viral infections. Ophthalmology 88: 1377-1381.

21. Azar MJ, Dhaliwal DK, Bower KS, Kowalski RP, Gordon YJ (1996) Possible consequences of shaking hands with your patients with epidemic keratoconjunctivitis. Am J Ophthalmol 121: 711-712.

22. Romanowski EG, Yates KA, Gordon YJ (2002) Topical corticosteroids of limited potency promote adenovirus replication in the Ad5/NZW rabbit ocular model. Cornea 21: 289-291.

23. Gordon YJ, Araullo-Cruz T, Romanowski EG (1998) The effects of topical nonsteroidal anti-inflammatory drugs on adenoviral replication. Arch Ophthalmol 116: 900-905.

24. Shiuey Y, Ambati BK, Adamis AP (2000) A randomized, double-masked trial of topical ketorolac versus artificial tears for treatment of viral conjunctivitis. Ophthalmology107: 1512-1517.

25. Romanowski EG, Pless P, Yates KA, Gordon YJ (2005) Topical cyclosporine A inhibits subepithelial immune infiltrates but also promotes viral shedding in experimental adenovirus models. Cornea 24: 86-91.

26. Kinchington PR, Romanowski EG, Gordon YJ (2005) Prospects for adenovirus antivirals. J Antimicrob Chemother 55: 424-429.
27. Hillenkamp J, Reinhard T, Ross RS, Böhringer D, Cartsburg O, et al. (2002) The effects of cidofovir $1 \%$ with and without cyclosporin a $1 \%$ as a topical treatment of acute adenoviral keratoconjunctivitis: a controlled clinical pilot study. Ophthalmology 109: 845-850.

28. Tabbara KF, Jarade EF (2001) Ganciclovir effects in adenoviral keratoconjunctivitis. in Investigative Ophthalmology \& Visual Science.

29. Teuchner B, Nagl M, Schidlbauer A, Ishiko H, Dragosits E, et al., Tolerability and efficacy of $\mathrm{N}$-chlorotaurine in epidemic keratoconjunctivitis--a double-blind, randomized, phase-2 clinical trial. J Ocul Pharmacol Ther 21: $157-165$

30. Isenberg Sj, Apt L, Campeas D (2002) Ocular applications of povidone-iodine. Dermatology 204: 92-95.

31. Isenberg SJ, Apt L, Valenton M, Del Signore M, Cubillan L, et al. (2002) A controlled trial of povidone-iodine to treat infectious conjunctivitis in children. Am J Ophthalmol 134: 681-688.

32. Pelletier JS, Stewart K, Trattler W, Ritterband DC, Braverman S, et al. (2009) A combination povidone-iodine $0.4 \%$ /dexamethasone $0.1 \%$ ophthalmic suspension in the treatment of adenoviral conjunctivitis. Adv Ther 26: 776-783

33. Melton R, Thomas R (2008) Stop EKC with a 'silver bullet'. Rev Optom 145.

34. Kovalyuk N, Kaiserman I, Mimouni M, Cohen O, Levartovsky S, et al. (2017) Treatment of adenoviral keratoconjunctivitis with a combination of povidone-iodine $1.0 \%$ and dexamethasone $0.1 \%$ drops: a clinical prospective controlled randomized study. Acta Ophthalmol 95: 686-692.

35. Trinavarat A, Atchaneeyasakul L-O (2012) Treatment of epidemic Keratoconjunctivitis with $2 \%$ povidone-iodine: a pilot study. J Ocul Pharmacol Ther 28: 53-58. 


\section{di \\ нвам}

Advances In Industrial Biotechnology | ISSN: 2639-5665

Advances In Microbiology Research | ISSN: 2689-694X

Archives Of Surgery And Surgical Education | ISSN: 2689-3126

Archives Of Urology

Archives Of Zoological Studies | ISSN: 2640-7779

Current Trends Medical And Biological Engineering

International Journal Of Case Reports And Therapeutic Studies | ISSN: 2689-310X

Journal Of Addiction \& Addictive Disorders | ISSN: 2578-7276

Journal Of Agronomy \& Agricultural Science | ISSN: 2689-8292

Journal Of AIDS Clinical Research \& STDs | ISSN: 2572-7370

Journal Of Alcoholism Drug Abuse \& Substance Dependence | ISSN: 2572-9594

Journal Of Allergy Disorders \& Therapy | ISSN: 2470-749X

Journal Of Alternative Complementary \& Integrative Medicine | ISSN: 2470-7562

Journal Of Alzheimers \& Neurodegenerative Diseases | ISSN: 2572-9608

Journal Of Anesthesia \& Clinical Care | ISSN: 2378-8879

Journal Of Angiology \& Vascular Surgery | ISSN: 2572-7397

Journal Of Animal Research \& Veterinary Science | ISSN: 2639-3751

Journal Of Aquaculture \& Fisheries | ISSN: 2576-5523

Journal Of Atmospheric \& Earth Sciences | ISSN: 2689-8780

Journal Of Biotech Research \& Biochemistry

Journal Of Brain \& Neuroscience Research

Journal Of Cancer Biology \& Treatment | ISSN: 2470-7546

Journal Of Cardiology Study \& Research | ISSN: 2640-768X

Journal Of Cell Biology \& Cell Metabolism | ISSN: 2381-1943

Journal Of Clinical Dermatology \& Therapy | ISSN: 2378-8771

Journal Of Clinical Immunology \& Immunotherapy | ISSN: 2378-8844

Journal Of Clinical Studies \& Medical Case Reports | ISSN: 2378-8801

Journal Of Community Medicine \& Public Health Care | ISSN: 2381-1978

Journal Of Cytology \& Tissue Biology | ISSN: 2378-9107

Journal Of Dairy Research \& Technology | ISSN: 2688-9315

Journal Of Dentistry Oral Health \& Cosmesis | ISSN: 2473-6783

Journal Of Diabetes \& Metabolic Disorders | ISSN: 2381-201X

Journal Of Emergency Medicine Trauma \& Surgical Care | ISSN: 2378-8798

Journal Of Environmental Science Current Research | ISSN: 2643-5020

Journal Of Food Science \& Nutrition | ISSN: 2470-1076

Journal Of Forensic Legal \& Investigative Sciences | ISSN: 2473-733X

Journal Of Gastroenterology \& Hepatology Research | ISSN: 2574-2566
Journal Of Genetics \& Genomic Sciences | ISSN: 2574-2485

Journal Of Gerontology \& Geriatric Medicine | ISSN: 2381-8662

Journal Of Hematology Blood Transfusion \& Disorders | ISSN: 2572-2999

Journal Of Hospice \& Palliative Medical Care

Journal Of Human Endocrinology | ISSN: 2572-9640

Journal Of Infectious \& Non Infectious Diseases | ISSN: 2381-8654

Journal Of Internal Medicine \& Primary Healthcare | ISSN: 2574-2493

Journal Of Light \& Laser Current Trends

Journal Of Medicine Study \& Research | ISSN: 2639-5657

Journal Of Modern Chemical Sciences

Journal Of Nanotechnology Nanomedicine \& Nanobiotechnology | ISSN: 2381-2044

Journal Of Neonatology \& Clinical Pediatrics | ISSN: 2378-878X

Journal Of Nephrology \& Renal Therapy | ISSN: 2473-7313

Journal Of Non Invasive Vascular Investigation | ISSN: 2572-7400

Journal Of Nuclear Medicine Radiology \& Radiation Therapy | ISSN: 2572-7419

Journal Of Obesity \& Weight Loss | ISSN: 2473-7372

Journal Of Ophthalmology \& Clinical Research | ISSN: 2378-8887

Journal Of Orthopedic Research \& Physiotherapy | ISSN: 2381-2052

Journal Of Otolaryngology Head \& Neck Surgery | ISSN: 2573-010X

Journal Of Pathology Clinical \& Medical Research

Journal Of Pharmacology Pharmaceutics \& Pharmacovigilance | ISSN: 2639-5649

Journal Of Physical Medicine Rehabilitation \& Disabilities | ISSN: 2381-8670

Journal Of Plant Science Current Research | ISSN: 2639-3743

Journal Of Practical \& Professional Nursing | ISSN: 2639-5681

Journal Of Protein Research \& Bioinformatics

Journal Of Psychiatry Depression \& Anxiety | ISSN: 2573-0150

Journal Of Pulmonary Medicine \& Respiratory Research | ISSN: 2573-0177

Journal Of Reproductive Medicine Gynaecology \& Obstetrics | ISSN: 2574-2574

Journal Of Stem Cells Research Development \& Therapy | ISSN: 2381-2060

Journal Of Surgery Current Trends \& Innovations | ISSN: 2578-7284

Journal Of Toxicology Current Research | ISSN: 2639-3735

Journal Of Translational Science And Research

Journal Of Vaccines Research \& Vaccination | ISSN: 2573-0193

Journal Of Virology \& Antivirals

Sports Medicine And Injury Care Journal | ISSN: 2689-8829

Trends In Anatomy \& Physiology | ISSN: 2640-7752

Submit Your Manuscript: https://www.heraldopenaccess.us/submit-manuscript 